\title{
Chemically Induced Splay Nematic Phase with Micron Scale Periodicity
}

Perri L. M. Connor and Richard J. Mandle*

*Richard.mandle@york.ac.uk

\begin{abstract}
Nematic liquid crystals lack positional order of their constituent molecules, which share an average orientational order only. Modulated nematic liquid crystal phases also lack positional order, but possess a periodic variation in this direction of average orientation. In the recently discovered splay nematic $\left(\mathrm{N}_{\mathrm{s}}\right)$ phase the average orientational order is augmented with a periodic splay deformation of orientation perpendicular to the director. In this communication we report the first example of a splay nematic phase which is chemically induced by mixing two materials, neither of which exhibit the $\mathrm{N}_{\mathrm{s}}$ phase. The splay-nematic phase is identified based on its optical textures, $\mathrm{X}$-ray scattering patterns, and small enthalpy of the associated phase transition. We measure the splay periodicity optically, finding it to be $\sim 9 \mu \mathrm{m}$. This unexpected generation of the splay-nematic phase through binary mixtures offers a new route to materials which exhibit this phase which complements ongoing studies into structure-property relationships and could accelerate the development of technologies utilising this remarkable polar nematic variant.
\end{abstract}

\section{Introduction}

Nematic liquid crystal phases, which possess an average orientational order of their constituent molecules but lack long range positional order, remain the cornerstone of the display industry. The discovery of nematic phases possessing periodic modulation of their orientation has generated significant interest due to the rarity, and typically importance, of new nematic ground states. ${ }^{1-5}$ The most widely studied of these recently observed nematic variants is the twist-bend nematic, in which the average orientational direction rotates about a cone along the optic axis giving rise to a helical structure with a periodicity of a few molecular lengths. ${ }^{6-8}$ Other modulated nematic phases, possibly twist bend nematic variants, have also been reported. ${ }^{9-11}$

Mertelj et al discovered a nematic phase with a periodically splayed local director, a splay nematic phase $\left(N_{s}\right.$, figure $\left.1 c\right),{ }^{12}$ which had been reported previously as a $N_{x}$ phase - i.e. a nematic phase of unknown structure. ${ }^{13}$ This experimental observation of a splay nematic ground state satisfied earlier predictions of such a phase of matter. ${ }^{14}$ The $\mathrm{N}_{\mathrm{S}}$ is related to the splay-bend nematic phase $\left(\mathrm{N}_{\mathrm{SB}}\right)$ described by Dozov through exchange of the splay and bend elastic constants; ${ }^{1,15}$ the modulation vector is parallel to the director in the $\mathrm{N}_{S B}$ and perpendicular in the $\mathrm{N}_{S}$ phase. Barbero and Lelidis recently discussed the possibility of periodic modulated splay-nematic phases that results from a negative value of $\mathrm{K}_{11} .{ }^{16}$ Moreover, and unlike the $\mathrm{N}_{\text {Тв }}$ phase, the splay nematic is fluid and exhibits a nematic-like orientational distribution function (ODF). ${ }^{17}$ The structure of the $\mathrm{N}_{\mathrm{s}}$ phase as proposed by Mertelj et $a /$ is polar, biaxial and antiferroelectric and therefore of significant interest for electrooptic devices. To date the $\mathrm{N}_{\mathrm{s}}$ phase has been found exclusively in polar materials with short alkyl chains and terminal nitro groups; ${ }^{18}$ this combination of structural features conspires to afford materials with high melting points and monotropic $\mathrm{N}_{\mathrm{s}}$ phases, therefore presenting an impediment 
to applications utilising this nematic ground state. We therefore sought a new method to obtain splay nematic materials; induction of the $\mathrm{N}_{\mathrm{s}}$ phase in mixtures of two materials that do not exhibit this phase, in a similar vein to the induction of the twist-bend nematic phase in binary mixtures. ${ }^{19-21}$

\section{Experimental}

Compound 1 can be isolated as a trace impurity during the synthesis of RM734; gratifyingly, it can also be synthesised in high yield by the action of EDC.HCl and DMAP on 4-((2,4dimethoxybenzoyl)oxy)benzoic acid, itself prepared according to ref ${ }^{18}$, as shown in Scheme 1. Further synthetic details are given in the SI to this article.

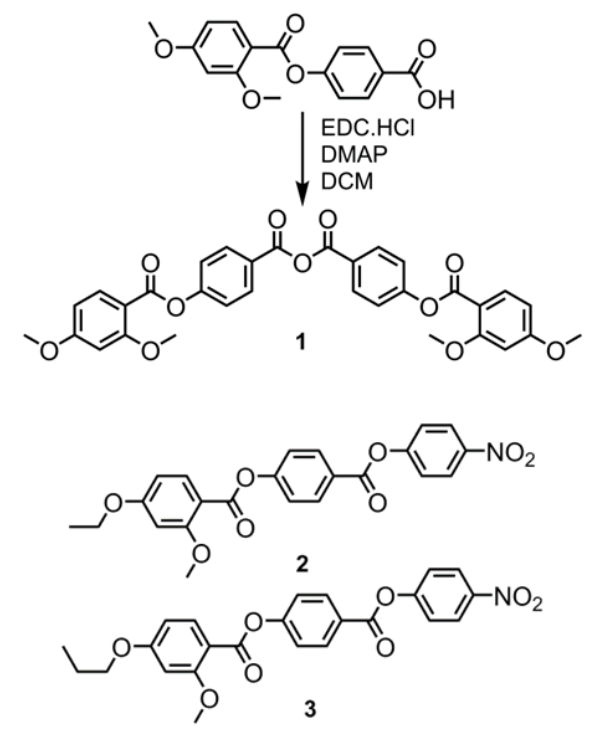

Scheme 1

Compounds $\mathbf{2}$ and $\mathbf{3}$, also shown in Scheme 1, were reported by us previously. ${ }^{13,18}$ Binary mixtures were prepared by weighing each component separately, mixing as solutions in chloroform, agitating in an ultrasonic bath for 10 minutes, and finally removing the chloroform with warming to $50{ }^{\circ} \mathrm{C}$ under a stream of nitrogen gas for $2 \mathrm{~h}$. Transition temperatures were determined by a combination of polarised optical microscopy (POM) and differential scanning calorimetry (DSC). X-ray scattering experiments (SAXS/WAXS) were performed using a Bruker D8 discover equipped with a custom built graphite rod furnace, with a magnetic field perpendicular to the incident beam used to achieve alignment of the sample. 


\section{Results}

Compound 1 retains some of the features of the rod-like splay-nematic material RM734; possessing lateral and terminal methoxy groups, but lacking the terminal nitro unit and being closer to a bentcore liquid crystal in terms of overall shape. Compounds $\mathbf{2}$ and $\mathbf{3}$ are analogous in structure to RM734 but longer terminal chains $\left(-\mathrm{OC}_{2} \mathrm{H}_{5}\right.$ and $-\mathrm{OC}_{3} \mathrm{H}_{7}$, respectively). Compound $\mathbf{1}$ is non mesogenic and crystallises on cooling from the isotropic liquid at $\sim 85^{\circ} \mathrm{C}$. Compound 2 exhibits nematic and splaynematic phases and compound $\mathbf{3}$ exhibits only a nematic phase, forming a glass when cooled with a $\mathrm{T}_{\mathrm{g}}$ of around $5{ }^{\circ} \mathrm{C}$. Transition temperatures and associated enthalpies are given in table 1.

\begin{tabular}{|l|l|l|l|l|l|}
\hline No. & & $\mathrm{MP}$ & $\mathrm{T}_{\mathrm{g}}$ & $\mathrm{N}_{\mathrm{s}} \mathrm{N}$ & $\mathrm{N}$-Iso \\
\hline $\mathbf{1}$ & $\mathrm{T}$ & 108.8 & - & - & - \\
& $\Delta \mathrm{H}$ & 63.0 & - & - & - \\
\hline $\mathbf{2}$ & $\mathrm{T}$ & 139.0 & - & 85.6 & 182.1 \\
& $\Delta \mathrm{H}$ & 34.8 & - & 0.2 & 0.6 \\
\hline $\mathbf{3}$ & $\mathrm{T}$ & 134.4 & $5^{\circ} \mathrm{C}$ & - & 165.0 \\
& $\Delta \mathrm{H}$ & 34.2 & - & - & 0.7 \\
\hline
\end{tabular}

Table 1: $\quad$ Transition temperatures $\left(\mathrm{T},{ }^{\circ} \mathrm{C}\right)$ and associated enthalpies of transition $\left(\Delta \mathrm{H}, \mathrm{kJ} \mathrm{mol}^{-1}\right)$ for compounds 1 and $\mathbf{2}$ as determined by DSC at a heat/cool rate of $10{ }^{\circ} \mathrm{C} \mathrm{min}^{-1}$. MP = melting point, $\mathrm{T}_{\mathrm{g}}=$ glass transition, $\mathrm{N}_{\mathrm{s}}-\mathrm{N}=$ splay nematic to nematic transition, $\mathrm{N}$-lso $=$ isotropisation point.

We constructed binary phase diagrams between compounds $\mathbf{1 / 2}$, and $\mathbf{2 / 3}$ in an attempt to rationalise how variations in molecular structure can inhibit the formation of the $N_{S}$ phase (Figure 1). In both phase diagrams the clearing point varies almost linearly with concentration, while the melting point displays a characteristic depression in the region of the eutectic point. Compound $\mathbf{1}$ and $\mathbf{3}$ are both found to suppress the $\mathrm{N}_{\mathrm{s}}$ phase exhibited by compound $\mathbf{2}$ in binary mixtures; we find that in both phase diagrams once the concentration of splay nematic host material drops below $50 \mathrm{wt} \%$ the $\mathrm{N}_{s}$ phase is not observed. Linear extrapolation of the $\mathrm{N}_{\mathrm{s}} \mathrm{N}$ transition temperature allows us to estimate a virtual $\mathrm{N}_{\mathrm{S}}-\mathrm{N}$ transition temperature for $\mathbf{1}$ and $\mathbf{3}$, giving values of $-10{ }^{\circ} \mathrm{C}$ and $-25^{\circ} \mathrm{C}$, respectively.
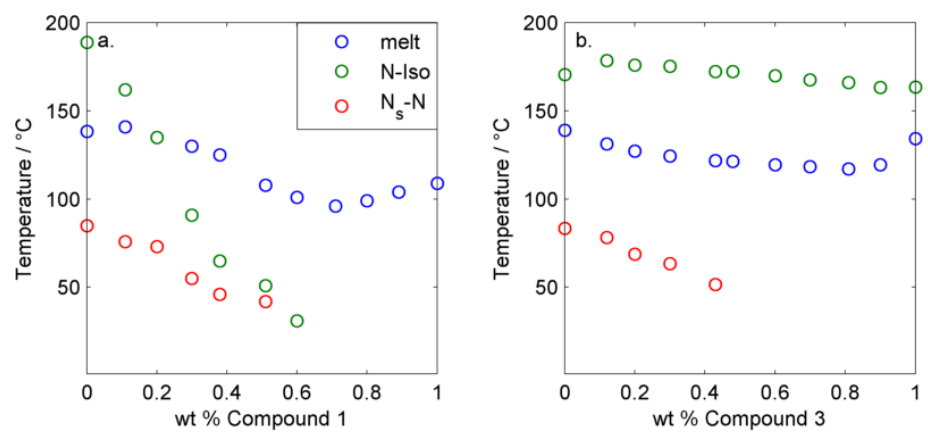
Figure 1: $\quad$ Transition temperatures $\left({ }^{\circ} \mathrm{C}\right)$ as a function of concentration (wt $\left.\%\right)$ for binary mixtures (wt \%) of (a) compound $\mathbf{1}$ and compound $\mathbf{2}$, and (b) compound $\mathbf{2}$ and $\mathbf{3}$.

We next prepared binary mixtures between the anhydride $\mathbf{1}$ and the nematogen $\mathbf{3}$, with the aim of chemically inducing the $\mathrm{N}_{S}$ phase in binary mixtures of these two materials (Figure 2). Over the phase diagram we observe that, as expected, increasing the concentration of the non-mesogenic component 1 reduces the clearing point. In terms of melting point we find the eutectic blend to be around $45 \mathrm{wt} \%$ 1 which agrees reasonably well with the predicted value of $39 \mathrm{wt} \%{ }^{22}$

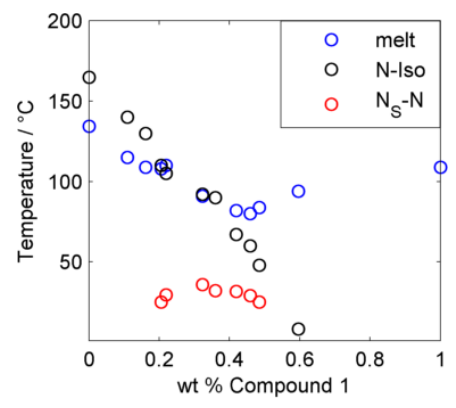

Figure 2: $\quad$ Transition temperatures $\left({ }^{\circ} \mathrm{C}\right)$ as a function of concentration (wt $\left.\%\right)$ for binary mixtures (wt \%) of compound $\mathbf{1}$ and compound $\mathbf{3}$.

At low concentrations ( $<20 \mathrm{wt} \%$ ) of 1 , we observe the same mesophase behaviour as seen in compound 2, namely only a nematic phase. Mixtures containing above $60 \mathrm{wt} \%$ of $\mathbf{1}$ are non mesogenic. Between these two values we find a monotropic splay-nematic phase, a remarkable observation considering neither of the two materials used in mixtures exhibit this modulated nematic modification. The occurrence of the $N_{S}$ phase here is not simply due to depression of the melt/recrystalisation temperature; at low concentrations of $\mathbf{1}$ mixtures undergoes glassification, whereas at high concentrations of $\mathbf{1}$ mixtures do not exhibit any latent mesophase. The splaynematic phase is observed at higher concentrations of both $\mathbf{1}$ and $\mathbf{3}$ than is seen when either of these materials are mixed with the bona fide splay nematic host $\mathbf{2}$. In all cases the enthalpy associated with the $\mathrm{N}_{\mathrm{s}} \mathrm{N}$ transition was smaller than that of the clearing point, mirroring the behaviour seen in neat materials. ${ }^{13,18}$ 


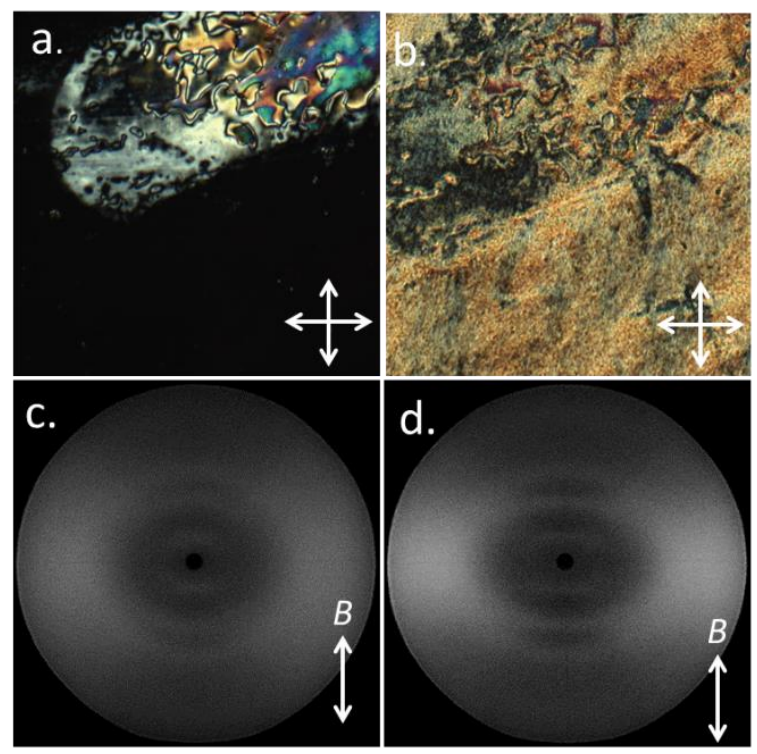

Figure 3: Photomicrographs (x100) of a binary mixture of $34 \mathrm{wt} \%$ compound 1 and $66 \%$ compound 3: (a) in the nematic phase at $88{ }^{\circ} \mathrm{C}$; (b) in the $\mathrm{N}_{\mathrm{s}}$ phase at $25^{\circ} \mathrm{C}$. Each photomicrograph presents roughly the same area of the slide; the width of the image is approximately $230 \mu \mathrm{m}$. Magnetically aligned two-dimensional X-ray scattering patterns of a binary mixture of 34 wt\% compound 1 and $66 \%$ compound 3 : (c) in the nematic phase at $80^{\circ} \mathrm{C}$; (d) in the $\mathrm{N}_{s}$ phase at $29^{\circ} \mathrm{C}$.

Phase identification was made by POM and SAXS; representative photomicrographs and 2D SAXS patterns are given in Figure 3. Identification of the 'classical' nematic phase via POM is trivial; however the splay-nematic phase shares almost the same optical textures as the preceding nematic and therefore phase assignment is perhaps more contentious. We find that the schlieren texture of the higher temperature nematic phase is preserved in the lower temperature phase, albeit with a notable change in birefringence. Some regions of the $\mathrm{N}_{\mathrm{S}}$ phase appear optically homogenous, whereas others - typically those close to defects or disclination lines - appear inhomogeneous, presumably as a result of the physical dimensions of the splay modulation period. Regions that are homeotropically aligned in the upper temperature nematic phase transform to be birefringent in the lower temperature nematic (Fig 3b), and also typically display the inhomogeneity observed in the schlieren texture. The lack of Bragg scattering in X-ray scattering experiments confirms that both the upper and lower temperature nematic phases are indeed nematic-like and are not smectic modifications. The X-ray scattering patterns are comparable to those of other $\mathrm{N}_{\mathrm{s}}$ materials, namely multiple weak scattering peaks parallel to the aligning magnetic field (Figure 3c, 3d). In the present case, the lack of angular separation between scattering parallel and perpendicular to the aligning magnetic field prevents measurement of orientational order.

Examination of optical textures at higher magnification $(x 400)$ reveals the inhomogeneity to be a periodic stripe texture (Fig 4a). We measured the periodicity in the optical texture of the splay nematic phase for a binary mixture of 34 wt\% compound 1 and $66 \%$ compound 3 as follows. The binary mixture was filled into a $5 \mu \mathrm{m}$ cell treated to give planar alignment by heating into the isotropic liquid, before 
cooling to ambient temperature $\left(22^{\circ} \mathrm{C}\right)$. Using a calibrated microscope objective, images were captured via a digital camera and converted to grayscale. Here we define a profile as the intensity values of pixels along a single line segment drawn on the image (blue lines in Figure $4 a$ and $4 b$ ); locations for profiles were selected manually due to the polydomain nature of the splay-nematic phase. We took a total of 107 profiles, giving a total of 360 periods studied. In the proposed structure of the $\mathrm{N}_{\mathrm{s}}$ phase the splay modulation is perpendicular to the director, thus the distance between two bright (or dark) regions in the periodic stripe texture is equal to one half of the modulation period (Figure 4c). We find mean and median values of $9.1 \mu \mathrm{m}$ and $8.0 \mu \mathrm{m}$ respectively (Figure $4 \mathrm{~d}$ ), with a standard deviation of $3.3 \mu \mathrm{m}$. To a first approximation, the standard deviation in our measurement can be understood to result from two unrelated effects: a profile being taken at an angle other than $90^{\circ}$ to the modulation period (giving larger values), and the plane of the splay modulation period not being perpendicular to the plane of the substrate (giving smaller values); in future the contribution of both of these effect could probably be minimised by some form of surface treatment of the substrate, however for the purpose of this communication the precision of these present measurements is sufficient. We are encouraged that our results agree with the measured splay periodicity recently reported by Sebastián et al. ${ }^{23}$
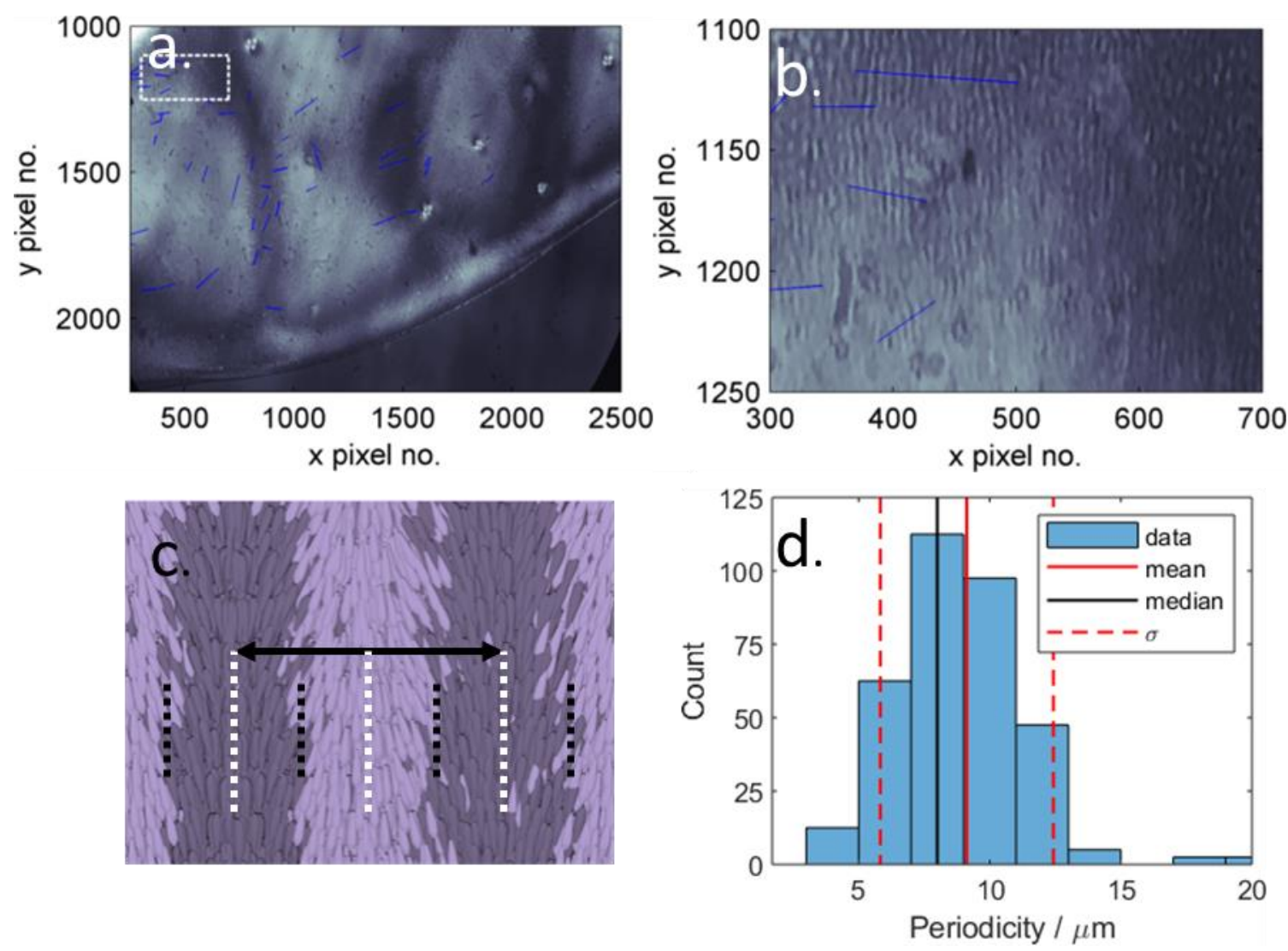

Figure 4: $\quad$ Periodicity observed in a binary mixture of $34 \mathrm{wt} \%$ compound 1 and $66 \%$ compound 3 confined in a $5 \mu \mathrm{m}$ cell at $22^{\circ} \mathrm{C}$ : (a) Greyscale photomicrograph ( $\left.x 400\right)$ of the optical texture, (b) close up of the area highlighted in white in (a); (c) proposed structure of the $\mathrm{N}_{\mathrm{s}}$ phase, adapted from [12], dashed lines indicating optically dark/light regions, 
and the arrow showing one splay modulation period; (d) histogram of measured optical periodicity from image profiles with the mean, median and one standard deviation from the mean indicated. Blue lines in (a) and (b) correspond to profiles taken along the image used in calculating the periodicity.

Typical splay-nematic materials, such as RM734 and the closely related compound 2, possess a minimal aliphatic content and a large transverse molecular electric dipole moment. The short chain means that the molecules are, to a first approximation, rod- or wedge- shaped. When the length of the terminal alkyl chain is increased (as in compound 3 ) the $\mathrm{N}_{\mathrm{s}}$ phase is suppressed. ${ }^{18}$ Similarly, results to date have shown that replacement of the nitro group with any other polar functional group eliminates the splay-nematic phase, thus it is unsurprising that compound $\mathbf{1}$ - which lacks a nitro group and the prerequisite rod- or wedge- shape - does not exhibit the splay nematic phase in its neat state. ${ }^{18}$ Indeed, the molecular shape of $\mathbf{1}$ is typical of that of a bent-core liquid crystal (see $\mathrm{SI})$. The ability of 1 to chemically induce the $\mathrm{N}_{\mathrm{s}}$ phase is most likely attributable to softening of the splay elastic constant, perhaps due to the flexoelectricity of the bent-core material used in this work, 24,25 which is expected to be large. ${ }^{26}$

Typical bent-core materials incorporate long terminal chains as a means of reducing melting points and/or promoting the occurrence of ' $B$ ' phases, which are effectively polar smectic and columnar phase variants. ${ }^{27}$ Compound $\mathbf{1}$ has minimal aliphatic content and so is expected to have lack the tendency to induce $B$ phases when mixed with a nematic host. Thus, it may be that other bent-core materials are not capable of induction of a splay-nematic phase as they preferentially induce polar smectic or columnar phases before the $\mathrm{N}_{\mathrm{s}}$ phase can form. ${ }^{28}$ Future optimisation, both of nematic host and bent-core additive, might be a useful route to generating room temperature splay-nematic materials for device use.

\section{Conclusions}

We have demonstrated the chemical induction of the splay-nematic phase $\left(\mathrm{N}_{\mathrm{s}}\right)$ by adding a nonmesogenic bent-core material to a nematic host. Neither material exhibits the $\mathrm{N}_{\mathrm{S}}$ phase in their neat state, but at certain concentrations we observe the splay-nematic phase which we identify based on its optical textures, X-ray scattering patterns, and small enthalpy of the associated phase transition. The proposed structure of splay-nematic phase is biaxial, and while bent-core additives such as $\mathbf{1}$ are not essential for the formation of the $\mathrm{N}_{\mathrm{S}}$ phase, the discovery that this phase can be induced offers a new route to splay-nematic materials which is complementary to the ongoing studies into the structure-property relationship. It is also somewhat gratifying that bent-core liquid crystals - which have been studied extensively for hints of as yet elusive nematic biaxiality - can in fact induce the biaxial splay-nematic phase. We show that it is possible to measure the splay nematic modulation period optically and find it to have an average value of 8-10 microns in the system studied.

\section{Acknowledgements}


PC and RJM would like to thank the Department of Chemistry at the University of York for funding, via the award of the Tony Semlyen Bursary to PC. The authors express thanks to Dr. Alenka Mertelj for useful discussions, ongoing collaboration, and for sharing data on measurement of the splay nematic periodicity by SHG.

\section{References}

1. I. Dozov, Europhys Lett, 2001, 56, 247-253.

2. M. Cestari, S. Diez-Berart, D. A. Dunmur, A. Ferrarini, M. R. de la Fuente, D. J. Jackson, D. O. Lopez, G. R. Luckhurst, M. A. Perez-Jubindo, R. M. Richardson, J. Salud, B. A. Timimi and H. Zimmermann, Phys Rev E Stat Nonlin Soft Matter Phys, 2011, 84, 031704.

3. D. Chen, M. Nakata, R. Shao, M. R. Tuchband, M. Shuai, U. Baumeister, W. Weissflog, D. M. Walba, M. A. Glaser, J. E. Maclennan and N. A. Clark, Phys Rev E Stat Nonlin Soft Matter Phys, 2014, 89, 022506.

4. $\quad$ R. J. Mandle, Soft Matter, 2016, 12, 7883-7901.

5. A. Jakli, O. D. Lavrentovich and J. V. Selinger, Rev Mod Phys, 2018, 90.

6. C. Zhu, M. R. Tuchband, A. Young, M. Shuai, A. Scarbrough, D. M. Walba, J. E. Maclennan, C. Wang, A. Hexemer and N. A. Clark, Phys Rev Lett, 2016, 116, 147803.

7. G. Singh, J. X. Fu, D. M. Agra-Kooijman, J. K. Song, M. R. Vengatesan, M. Srinivasarao, M. R. Fisch and S. Kumar, Phys Rev E, 2016, 92.

8. $\quad$ R. J. Mandle and J. W. Goodby, Phys Chem Chem Phys, 2019, 21, 6839-6843.

9. C. T. Archbold, E. J. Davis, R. J. Mandle, S. J. Cowling and J. W. Goodby, Soft Matter, 2015, 11, 7547-7557.

10. A. Knežević, M. Sapunar, A. Buljan, I. Dokli, Z. Hameršak, D. Kontrec and A. Lesac, Soft Matter, 2018, 14, 8466-8474.

11. R. J. Mandle and J. W. Goodby, Soft Matter, 2018, 14, 8846-8852.

12. A. Mertelj, L. Cmok, N. Sebastian, R. J. Mandle, R. R. Parker, A. C. Whitwood, J. W. Goodby and M. Copic, Phys Rev X, 2018, 8.

13. R. J. Mandle, S. J. Cowling and J. W. Goodby, Phys Chem Chem Phys, 2017, 19, 11429-11435.

14. H. Pleiner and H. R. Brand, Europhys Lett, 1989, 9, 243-249.

15. N. Chaturvedi and R. D. Kamien, eprint arXiv:1904.09210, 2019, arXiv:1904.09210.

16. G. Barbero and I. Lelidis, Liq Cryst, 2019, 46, 535-542.

17. R. J. Mandle and A. Mertelj, Phys Chem Chem Phys, 2019, DOI: 10.1039/C9CP03581H.

18. R. J. Mandle, S. J. Cowling and J. W. Goodby, Chem-Eur J, 2017, 23, 14554-14562.

19. K. Adlem, M. Čopič, G. R. Luckhurst, A. Mertelj, O. Parri, R. M. Richardson, B. D. Snow, B. A. Timimi, R. P. Tuffin and D. Wilkes, Phys Rev E, 2013, 88, 022503.

20. E. Ramou, Z. Ahmed, C. Welch, P. K. Karahaliou and G. H. Mehl, Soft Matter, 2016, 12, 888899.

21. E. Ramou, C. Welch, J. Hussey, Z. Ahmed, P. K. Karahaliou and G. H. Mehl, Liq Cryst, 2018, 45, 1929-1935.

22. D. S. Hulme and E. P. Raynes, J Chem Soc Chem Comm, 1974, DOI: DOI 10.1039/c39740000098, 98-99.

23. N. Sebastián, L. Cmok, R. J. Mandle, M. Rosario de la Fuente, I. Drevenšek Olenik, M. Čopič and A. Mertelj, Journal, 2019.

24. S. Dhakal and J. V. Selinger, Phys Rev E Stat Nonlin Soft Matter Phys, 2010, 81, 031704.

25. M. Čopič and A. Mertelj, Journal, 2019. 
26. J. Harden, B. Mbanga, N. Eber, K. Fodor-Csorba, S. Sprunt, J. T. Gleeson and A. Jakli, Phys Rev Lett, 2006, 97, 157802.

27. R. A. Reddy and C. Tschierske, J Mater Chem, 2006, 16, 907-961.

28. M. Chiappini, T. Drwenski, R. van Roij and M. Dijkstra, Phys Rev Lett, 2019, 123, 068001. 


\section{Chemically Induced Splay Nematic Phase with Micron Scale Periodicity}

\section{Supplementary Information}

Perri L. M. Connor and Richard J. Mandle*

*Richard.mandle@york.ac.uk

\section{Methods}

\subsection{General Techniques}

4-((2,4-Dimethoxybenzoyl)oxy)benzoic acid was prepared as described previously; ${ }^{1} \mathrm{EDC} . \mathrm{HCl}$ was purchased from Fluorochem, DMAP was purchased from SigmaAldrich, and solvents were purchased from Fisher Scientific. Reactions were monitored by thin layer chromatography (TLC) using an appropriate solvent system. Silica coated aluminium TLC plates used were purchased from Merck (Kieselgel 60 F-254) and visualised using UV light (254 nm). Column chromatography was performed

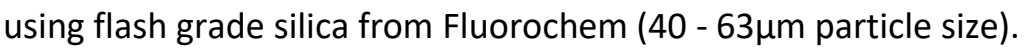

\subsection{Nuclear Magnetic Resonance}

NMR spectra were recorded on a JEOL ECS spectrometer operating at $400 \mathrm{MHz}\left({ }^{1} \mathrm{H}\right)$ or $100.5 \mathrm{MHz}$ $\left({ }^{13} \mathrm{C}\left\{{ }^{1} \mathrm{H}\right\}\right)$ as solutions in deuterated chloroform. Spectra were referenced to the residual protic solvent for ${ }^{1} \mathrm{H}(7.26 \mathrm{ppm}),{ }^{13} \mathrm{C}\left\{{ }^{1} \mathrm{H}\right\}$ to the resonance of $\mathrm{CDCl}_{3}$ (77.16 ppm).

\subsection{Mass Spectrometry}

Mass spectra were recorded on a Bruker compact time of flight mass spectrometer with both ESI and APCl sources, and we extend our gratitude to Mr. Karl Heaton of the University of York for obtaining MS data.

\subsection{Polarised Optical Microscopy}

Polarised optical microscopy was performed on a Zeiss Axioskop 40Pol microscope using a Mettler FP82HT hotstage controlled by a Mettler FP90 central processor. Photomicrographs were captured via either an InfinityX-21 MP digital camera (1 MP) or a Sony NEX 5R mirrorless digital camera (16 MP) mounted atop the microscope. Analysis of image profiles was performed in Matlab.

\subsection{Differential Scanning Calorimetry.}

Differential scanning calorimetry was performed on a Mettler DSC822 ${ }^{\mathrm{e}}$ fitted with an autosampler operating with Mettler Star ${ }^{\mathrm{e}}$ software and calibrated before use against an indium standard (onset = $156.55 \pm 0.2^{\circ} \mathrm{C}, \Delta \mathrm{H}=28.45 \pm 0.40 \mathrm{Jg}^{-1}$ ) under an atmosphere of dry nitrogen. 


\subsection{X-ray scattering}

Small angle X-ray diffraction was performed using a Bruker D8 Discover equipped with a temperature controlled, bored graphite rod furnace, custom built at the University of York. The radiation used was

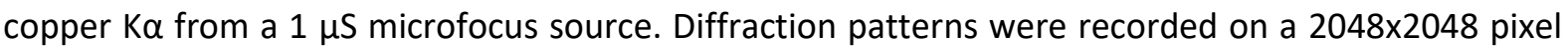
Bruker VANTEC 500 area detector set at a distance of $121 \mathrm{~mm}$ from the sample, allowing simultaneous collection of small angle and wide angle scattering data. Samples were filled into $1 \mathrm{~mm}$ capillary tubes and aligned with a pair of $1 \mathrm{~T}$ magnets. Diffraction patterns were collected as a function of temperature. Background subtraction and data processing was performed in Matlab.

\subsection{Computational Chemistry}

Quantum chemical calculations were performed using the Gaussian 09 revision 1.03 suite of programmes. ${ }^{2}$ Output files were aligned and visualised using VMD. ${ }^{3}$

\section{Chemical Characterisation}<smiles>COc1ccc(C(=O)Oc2ccc(C(=O)OC(=O)c3ccc(OC(=O)c4ccc(OC)cc4OC)cc3)cc2)c(OC)c1</smiles>

1: $\quad 4-((2,4-d i m e t h o x y b e n z o y l) o x y)$ benzoic anhydride

A suspension of 4-((2,4-dimethoxybenzoyl)oxy)benzoic acid (302 mg, $1 \mathrm{mmol}),{ }^{1} \mathrm{EDC} . \mathrm{HCl}(382 \mathrm{mg}, 1$ mmol), and DMAP (1 mg) in anhydrous THF ( $5 \mathrm{ml}$ ) was vigorously stirred for $24 \mathrm{~h}$. The solvent was then removed in vacuo. The crude material was passed through a plug of $\mathrm{SiO}_{2}$, eluting with 3:1 EtOAc/hexanes. The chromatographed material was recrystalised from toluene, giving the title compound as a colourless crystalline solid.

Yield: $\quad 240 \mathrm{mg}(82 \%)$

Rf: $\quad 0.53(D C M)$

${ }^{1} \mathrm{H}$ NMR: $\quad 3.89\left(6 \mathrm{H}, \mathrm{s}, \mathrm{ArO}-\mathrm{CH}_{3}\right), 3.93\left(6 \mathrm{H}, \mathrm{s}, \operatorname{ArO}-\mathrm{CH}_{3}\right), 6.53(2 \mathrm{H}, \mathrm{d}, J=2.3 \mathrm{~Hz}, \mathrm{Ar} \underline{\mathrm{H}}), 6.57(2 \mathrm{H}$, $\mathrm{dd}, J=2.3 \mathrm{~Hz}, J=8.8 \mathrm{~Hz}, \operatorname{Ar} \underline{\mathrm{H}}), 7.37(4 \mathrm{H}, \mathrm{ddd}, J=2.3 \mathrm{~Hz}, J=3.3 \mathrm{~Hz}, J=9.3 \mathrm{~Hz}, \operatorname{Ar} \underline{\mathrm{H}})$, $8.07(2 \mathrm{H}, \mathrm{d}, J=8.8 \mathrm{~Hz}, \operatorname{Ar} \underline{\mathrm{H}}), 8.28(4 \mathrm{H}, \mathrm{ddd}, J=2.3 \mathrm{~Hz}, J=3.3 \mathrm{~Hz}, J=9.3 \mathrm{~Hz}, \operatorname{Ar} \underline{\mathrm{H}})$

${ }^{13} \mathrm{C}\left\{{ }^{1} \mathrm{H}\right\}$ NMR: $\quad 55.78,56.19,99.12,105.30,110.53,121.90,127.99,130.59,134.01,154.16,161.66$, $162.41,164.08,166.61$

MS (APCI): $\quad 587.1577$ (calcd. for $\mathrm{C}_{32} \mathrm{H}_{26} \mathrm{O}_{11}: 587.1548, \mathrm{M}+\mathrm{H}$ ) 


\section{Conformational Analysis of Compound 1}
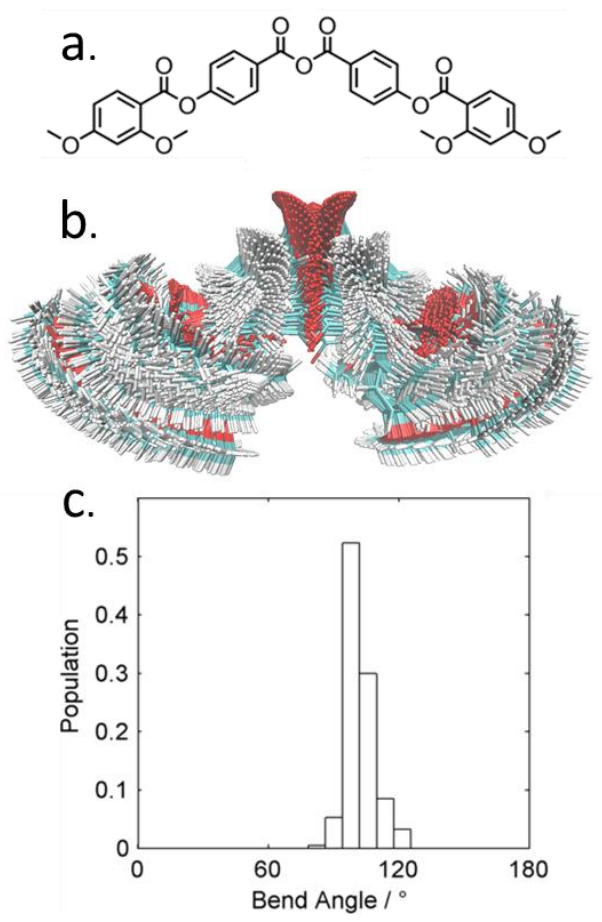

Figure SI1: $\quad$ (a) Molecular structure of compound 1; (b) overlaid conformers of compound 1 calculated as described in the text at the WB97XD/6-31G(d) level of DFT; (c) probability distribution of bend angles of compound 1 .

We considered that compound 1 may exhibit some unexpected shape due to the presence of a central carboxylic acid anhydride, and so we performed fully relaxed scans on compound $\mathbf{1}$ (at the wB97XD/6-31G(d) level of DFT), allowing the two $C(O)$-O bonds of the carboxylic acid anhydride to undergo rotation ( $15^{\circ}$ step size) while also allowing carboxylate esters to undergo twofold rotation about the $\mathrm{C}_{\mathrm{Ar}} \mathrm{C}(\mathrm{O})$ and $\mathrm{C}_{\mathrm{Ar}}-\mathrm{O}$ bonds to give a library of conformers (Figure SI1). Assuming a Boltzmann population at $298 \mathrm{~K}$, we calculate the probability weighted average bend angle to be centred on $100^{\circ}$ with a FWHM of $12^{\circ}$, we consider this typical for a 'semi-rigid' bent-core material. 


\section{References}

1. R. J. Mandle, S. J. Cowling and J. W. Goodby, Chem-Eur J, 2017, 23, 14554-14562.

2. M. J. Frisch, G. W. Trucks, H. B. Schlegel, G. E. Scuseria, M. A. Robb, J. R. Cheeseman, G. Scalmani, V. Barone, B. Mennucci, G. A. Petersson, H. Nakatsuji, M. Caricato, X. Li, H. P. Hratchian, A. F. Izmaylov, J. Bloino, G. Zheng, J. L. Sonnenberg, M. Hada, M. Ehara, K. Toyota, R. Fukuda, J. Hasegawa, M. Ishida, T. Nakajima, Y. Honda, O. Kitao, H. Nakai, T. Vreven, J. A. Montgomery Jr., J. E. Peralta, F. Ogliaro, M. J. Bearpark, J. Heyd, E. N. Brothers, K. N. Kudin, V. N. Staroverov, R. Kobayashi, J. Normand, K. Raghavachari, A. P. Rendell, J. C. Burant, S. S. Iyengar, J. Tomasi, M. Cossi, N. Rega, N. J. Millam, M. Klene, J. E. Knox, J. B. Cross, V. Bakken, C. Adamo, J. Jaramillo, R. Gomperts, R. E. Stratmann, O. Yazyev, A. J. Austin, R. Cammi, C. Pomelli, J. W. Ochterski, R. L. Martin, K. Morokuma, V. G. Zakrzewski, G. A. Voth, P. Salvador, J. J. Dannenberg, S. Dapprich, A. D. Daniels, Ö. Farkas, J. B. Foresman, J. V. Ortiz, J. Cioslowski and D. J. Fox, Gaussian 09, 2009.

3. W. Humphrey, A. Dalke and K. Schulten, J Mol Graph, 1996, 14, 33-38, 27-38. 